\title{
Risk factors for having diabetic retinopathy at first screening in persons with type 1 diabetes diagnosed under 18 years of age
}

\author{
James Rafferty ${ }^{1,2} \quad$ David R. Owens $^{1} \quad$ Stephen D. Luzio $^{1} \quad$ Patrick Watts $^{3}$
}

\author{
Ashley Akbari $^{4} \quad$ Rebecca L. Thomas ${ }^{1}$
}

\begin{abstract}
Objective: To determine the risk factors for having diabetic retinopathy (DR) in children and young people (CYP) with type 1 diabetes (T1DM) at first screening.

Methods: Records from the Diabetes Eye Screening Wales (DESW) service for people in Wales, UK, with T1DM diagnosed under age 18 years were combined with other electronic health record (EHR) data in the Secure Anonymised Information Linkage (SAIL) Databank. Data close to the screening date were collected, and risk factors derived from multivariate, multinomial logistic regression modelling.

Results: Data from 4,172 persons, with median (Lower Quartile, Upper Quartile) age $16.3(13.0,22.3)$ years and duration of diabetes $6.6(2.3,12.3)$ years were analysed. $62.6 \%(\mathrm{n}=2,613)$ had no DR, 26.7\% $(\mathrm{n}$ $=1,112)$ background DR and 10.7\% $(\mathrm{n}=447)$ had referable DR $(\mathrm{RDR})$. No RDR was observed under 19 years of age. Factors associated with an increased risk of DR were diabetes duration, elevated $\mathrm{HbA}_{1 \mathrm{c}}$ and diastolic blood pressure. People diagnosed with T1DM before age 12 years had an odds ratio of 1.23 for developing DR for each year they had diabetes, compared with an odds ratio of 1.34 for those diagnosed at age 12 years or older.
\end{abstract}

Conclusions: This study found that $37.4 \%$ of the study cohort had DR at first screening, the risk being greater the longer the duration of diabetes or higher the $\mathrm{HbA}_{1 \mathrm{c}}$ and diastolic blood pressure. In addition, people diagnosed at 12 years of age or over were more likely to have DR with each additional year with diabetes.

\footnotetext{
${ }^{1}$ Diabetes Research Unit Cymru, Swansea University Medical School, Singleton Park, Swansea, UK

${ }^{2}$ Corresponding author. Email: j.m.rafferty@swansea.ac.uk

${ }^{3}$ Department of Ophthalmology, University Hospital of Wales, Cardiff, UK

${ }^{4}$ Health Data Research UK, Swansea University Medical School, Singleton Park, Swansea, UK
} 
Running Head: Risk factors for retinopathy at first screening in T1DM 


\section{Introduction}

Visual impairment and blindness, as a consequence of diabetic retinopathy (DR), are amongst the most feared complications of diabetes. The incidence and prevalence of sight-threatening DR (STDR) has however been slowly decreasing over the last several decades despite the increase in the prevalence of diabetes (ref.1-7). It has been recently reported in England and Wales that DR is no longer the leading cause of blindness in the working age population (ref.8). Also in a retrospective analysis of newly recorded certifications of visual impairment in Wales during 2007-2015 sight loss was reduced by 50\% (ref.9). These observations may reflect the cumulative impact of better management of diabetes, the introduction of screening programs, better management of risk factors and earlier and more effective ophthalmologic interventions.

Good glycaemic and blood pressure management are pivotal in both primary prevention and the prevention of progression of DR. The introduction of intensive insulin therapy to optimise glycaemic management in children has been observed to have a beneficial effect on DR in multiple studies (ref.10-12). In children aged 13-17 years with type 1 diabetes (T1DM) the risk of developing DR was reduced by 53\% (ref.10) while in children and young people (CYP) aged 12 to 20 years DR was also reduced by $12 \%$ to $52 \%$ (ref.11). The benefit of such intensive management in the adolescent years remains evident many years later (legacy effect) even when $\mathrm{HbA}_{1 c}$ values deteriorate, becoming similar to those undergoing conventional insulin therapy (ref.12). Currently, the treatment for STDR, which encompasses severe non-proliferative DR (preproliferative DR [PPDR] and proliferative DR (PDR), is primarily by laser photocoagulation and/or intravitreal injections of inhibitors of vascular endothelial growth factors (anti-VEGF). The relatively recent addition of anti-VEGF treatment has improved visual outcomes in those with PDR and/or clinically significant macular oedema (CSMO) (ref.13). Vitrectomy may also be required when these measures are considered inadequate. It is well accepted that DR remains asymptomatic until it reaches an advanced stage (STDR) and that the benefit from treatment is best achieved early. This is the basis for the introduction of screening for DR, which has been shown to be of clinical benefit but also cost-effective (ref.14). The detection of any DR should help to emphasise the need for improving glycaemic and blood pressure management, to prevent progression to STDR. 
Previous studies have shown that approximately $0.3 \%$ of the Welsh population and $0.2 \%$ of CYP under 16 years have T1DM (ref.15, 16). The prevalence of DR in children and young people (CYP) with diabetes is low and extremely rare prior to puberty $($ ref.17, 18). The prevalence of DR has been found in CYP with diabetes to range between $10.5 \%$ and $57.6 \%$ depending on the age, duration of diabetes, methods of detecting DR and the care setting (ref.18-30). The youngest ages at which DR and STDR have been recorded is 5 and 15 years respectively, with the shortest duration of diabetes being 5 years and only five cases of STDR have been observed in children below the age of 18 years (ref.29, 31). However, these studies involved relatively small numbers and therefore there is a need to more clearly understand the epidemiology of DR and related risk factors in a population with T1DM diagnosed below the age of 18 years.

Systematic screening programmes for DR were introduced in the UK in 2003 with the recommendation to begin screening from the age of 12 years onwards (ref.32). However, the International Society for Paediatric and Adolescent Diabetes (ISPAD) recommends annual screening to begin earlier from the age of 10 years or at the onset of puberty, if this is earlier (ref.33). In Wales there exists a single national community based DR screening programme for all persons with diabetes aged 12 years and over using a standardised quality assured methodology for image capture and grading of diabetic retinopathy, the guidelines for which originated from the Airlie House classification and its modified version used in the Early Treatment Diabetic Retinopathy Study (ref.34, 35) which was simplified for the purpose of populations studies in the UK (ref.36). Grading involves a primary grader whose findings are checked by a secondary grader with differences resolved by a more senior tertiary grader to arrive at the final grading. Patients are referred to the hospital eye service if they have severe pre-proliferative DR, PDR and/or maculopathy for further assessment and treatment as required. This provided us with a unique opportunity to investigate the risk factors relating to DR in the population of children and young persons with T1DM diagnosed before the age of 18 years in Wales, at the time of their first screening event (ref.37).

\section{Methods}

The study database was derived from both primary care (Welsh Longitudinal General Practice dataset, WLGP) and the Diabetic Eye Screening Wales (DESW) dataset and held in the Secure Anonymised Information Linkage (SAIL) Databank (Swansea University). SAIL is a repository of routinely collected 
electronic health record (EHR) data for people living in or receiving medical services in Wales (ref.38, 39). This study was reviewed by the independent Information Governance Review Panel (IGRP) of the SAIL Databank and approved under the ID: 0493. Ethical approval was not required since only anonymised data was used.

\section{Data preparation}

The study cohort consisted of people in Wales diagnosed with T1DM under the age of 18 years. The method used to identify persons with T1DM necessitated a recorded diagnosis of T1DM plus a prescription for insulin close to their earliest diagnosis date, or a hospital inpatient episode because of diabetic ketoacidosis, or a prescription for a medical device used in the management of T1DM (blood glucose and ketone monitoring equipment, for example, monitors and testing strips) on at least 5 occasions in the 12 -months following diagnosis. In addition, the Brecon cohort, which is a national register of persons with T1DM diagnosed while living in Wales below the age of 15 years (ref.40) was also used to ensure the cohort was as complete as possible.

DESW aims to conduct DR screening annually in all persons with diabetes registered with a GP located in Wales that meet the eligibility criteria (most notably, persons must be 12 years or older). When a person attends screening, after testing visual acuity, two $45^{\circ}$ retinal fundus photographs (one centred on the fovea, and one nasal view) are captured for each eye following mydriasis. Trained graders then assess the images for the presence of diabetic retinopathy, with images graded according to a standardised grading protocol (ref.37). The initial dataset consisted of the findings from the initial eye screening event which resulted in a successful assessment for at least one eye. In addition to the DR grading the current age, age at diagnosis of diabetes, duration of diabetes, gender and whether the person was referred to a hospital eye department were recorded. The following data from primary care GP or reference sources obtained within 6 months of the date of initial DR screening were also included in the dataset: HbA1c, systolic and diastolic blood pressure, serum cholesterol, low density lipoprotein (LDL), high density lipoprotein (HDL), triglycerides, creatinine and Body Mass Index (BMI). Since this data was derived from the WLGP data, its availability depended on whether the test was performed by one of the $76 \%$ of general practices contributing data to the SAIL 

years was also added to the data to enable modelling of interactions with duration of diabetes. included in this study. The extract of the DESW data in the SAIL Databank used in this study ended at the end of January 2018.

\section{Statistical Methods}

Median and quartiles are reported as measured values are typically not normally distributed. A univariate analysis was conducted to investigate differences between the two groups for each individual variable. For continuous variables the Mann-Whitney U test was employed while categorical variables were investigated using Pearson's $\chi^{2}$ test. Secondly, multivariate models were constructed to compare a reference group consisting of people with no DR with two comparison groups: (i) people with evidence of any DR which was evaluated using binomial logistic regression and (ii) people with background diabetic retinopathy (BDR) or referable diabetic retinopathy (RDR, PPDR or worse) separately, which was evaluated using multinomial logistic regression.

Variables from the univariate analysis that were different between groups were used in the initial multivariate models and backwards stepwise logistic regression was performed until only those variables that differed significantly remained in the model. People diagnosed with T1DM before the age of 12 years are usually managed less intensively than those diagnosed after 12 years of age. Therefore, the model included a term that allowed for the interaction between the duration of diabetes and whether the person was diagnosed with T1DM under age 12 years or not. The logical variables indicating whether the person was diagnosed before the age of 12 years were retained regardless of whether they differed between groups, in order to evaluate their interaction with the duration of diabetes. In each of the logistic regression models, Nagelkere's Pseudo $\mathrm{R}^{2}$ (denoted $\mathrm{R}^{2}{ }_{\mathrm{N}}$ ) and the in-sample prediction accuracy, A, were used to evaluate the model's goodness of fit. 
In Wales, during 2003 to 20018, 4495 people were diagnosed with T1DM under the age of 18 years and invited for DR screening from the age of 12 onwards. $305(6.7 \%)$ did not attend screening and of the remaining 4190 people only $18(0.4 \%)$ had ungradable images at their first screening event. The median age of the study cohort at the time of T1DM diagnosis was 10.6 years and at initial DR screening was 16.3 years with a median duration of diabetes of 6.6 years. The median $\mathrm{HbA}_{1 \mathrm{c}}$ was $72.6 \mathrm{mmol} / \mathrm{mol}(8.8 \%)$ and blood pressure was 120/70 mmHg. (Table 1).

Of the 4,172 people with gradable images at their first screening event $62.6 \%(2,613)$ did not have any evidence of DR, $26.7 \%(1,112)$ had BDR and $10.7 \%$ (447) had RDR with 4.1\% (173) having proliferative DR in one or both eyes (Figure 1). Those who presented with any DR at their first screening event had higher $\mathrm{HbA}_{1 \mathrm{c}}$, blood pressure, LDL, cholesterol, creatinine and a longer duration of diabetes and these differences were even greater in those who presented with a referable level of DR (Supplementary table 1).

People who had had diabetes for a longer time were more likely to have DR at first screening, with the proportion of the population with DR increasing with increasing duration of diabetes almost linearly up to approximately 17 years duration (Figure 2a). After 5, 10, 15 and 20 years of diabetes duration $11.0 \%, 38.6 \%$, $68.4 \%$ and $83.9 \%$ respectively had evidence of BDR. RDR was only observed in those people having had diabetes for at least 8 years, thereafter the proportion of people with RDR increased linearly (Figure 2a). We found, after 10, 15 and 20 years duration $4.6 \%, 27.9 \%$ and $53.6 \%$ of people had RDR respectively. None of the CYP had evidence of RDR before the age of 18 years (Figure 2b). We observed that $11.4 \%$ of 12 year olds at first screening had evidence of early DR, increasing to $31.9 \%$ for 18 year olds (Figure 2b). A smaller proportion of people aged under 12 years at diagnosis of T1DM had DR at first screening than people diagnosed at age 12 years or older when controlling for duration of diabetes (Figure 2c). Those people diagnosed with T1DM at or over the age of 12 years acquired an additional risk of developing DR for each year they had T1DM than people diagnosed under the age of 12 years (Table 2). This difference in the proportion of people with DR persisted until approximately 20 years duration of diabetes, when the proportion of people with DR in both groups became comparable (Figure 2c). 
In a multivariate binomial logistic regression analysis, presenting at first screening with an elevated $\mathrm{HbA}_{1 c}$ (odds ratio [OR] 1.09) and duration of diabetes (OR 1.23 for people diagnosed under age 12 and 1.34 for people diagnosed at age 12 or older) carried an increased risk of having DR (Table 2a). In the multivariate, multinomial model increased $\mathrm{HbA}_{1 \mathrm{c}}$, diastolic blood pressure and duration of diabetes were observed to increase the risk of BDR and RDR, with duration of diabetes having the greatest effect (OR 1.22 for BDR

\section{Discussion}

This study involved a large cohort (4172) of children and young people diagnosed with T1DM under the event. In this cohort the presence of any DR was seen in $37.4 \%$ and $10.7 \%$ had RDR although no one was found with RDR under the age of 18 years. The fraction of people with BDR at first screening increased almost linearly with age, with approximately $31.8 \%$ having BDR at first screening at age 18 . Although none of the cohort had RDR at their first screening before the age of 19 years there was a linear increase thereafter increasing to $30.1 \%$ at the age of 25 years at first screening. Increased diabetes duration, elevated $\mathrm{HbA}_{1 \mathrm{c}}$, and diastolic blood pressure conferred a higher risk of having any DR, BDR or RDR at first screening.

To our surprise our retinal graders recorded the presence of BDR in approximately $10 \%$ of our cohort within the first 2 years after diagnosis at variance with previous studies (ref.35, 42-44). This is difficult to explain but may in part reflect the high quality of retinal images acquired and the rigorous grading procedure at DESW and/or a prolonged asymptomatic period prior to the diagnosis of diabetes. Another contributing factor may be that many of the diagnoses of DR at this stage is acknowledged to rely on a small number of microaneurysms, or even a solitary one. Similarly, the DCCT study observed that $9.9 \%$ of people with type 1 diabetes had evidence of diabetic retinopathy within the first 2 years since diagnosis, based on 7-field stereoscopic colour retinal photographs, increasing to $15 \%$ with the addition of fluorescein angiography (ref.45). Consistent with many other studies (ref.46-48), we demonstrated in our study that the longer the duration of diabetes the greater the risk of developing DR. The proportion with BDR at 5 and 10 years was 
approximately $11.0 \%$ and $38.6 \%$ respectively, and whereas there was no RDR seen up to 8 years after diagnosis, at 10 and 20 years duration approximately $4.6 \%$ and $53.6 \%$ had developed RDR.

We also observed that a greater proportion of those diagnosed with T1DM after the age of 12 years had DR when compared to those diagnosed prior to 12 years for the same diabetes duration. The median time to DR in those diagnosed after the age of 12 years was 10 years in comparison to a median time of 12 years in those diagnosed before the age of 12 years. The adverse impact of puberty on the risk of progression of DR has been observed in many other populations (ref.42, 49, 50) although not in others (ref.51).

Our study also found that a higher $\mathrm{HbA}_{1 c}$ was a risk factor for $\mathrm{DR}$ at first screening which is in agreement with many previous studies performed in the UK (ref.5, 46), Europe (ref.47, 52) and the US (ref.48, 53). The finding that increased diastolic blood pressure specifically increases the risk of DR at first screening is

Other risk factors for DR found in some previous studies were $\mathrm{HbA}_{1 \mathrm{c}}$ variability, total cholesterol, HDL, age at diabetes diagnosis (ref.5, 52) and male gender (ref.47). However, in our study cohort we found total cholesterol, LDL, HDL, triglycerides and gender not to be associated with the occurrence of DR. It is difficult to compare our results with previous longitudinal studies due to differences in study population and design.

A limitation of this study was that persons having undertaken screening but did not have additional EHR data which included the putative risk factors of interest within six months of the screening which was required by the model and therefore were excluded from the cohort and subsequent analysis. Only if the measurement of $\mathrm{HbA}_{1 \mathrm{c}}$ is available within 6-months of the screening date is the person included in the model. Adding more variables to the model compounds this difficulty, leading to quite small cohorts due to the 
relatively high levels of missing data. The key factor that influences whether the data is missing or not is when the measurements were performed, and since these data are gathered at all times through the year the data can be considered to be missing at random and consequently will not affect the results of statistical modelling. This limitation would be common to all study designs that incorporate routine data. Furthermore, this study did not have access to data from the hospital based ophthalmological services to confirm the diagnoses of RDR. However, a great advantage of our study is that the cohort of persons with type 1 diabetes is much larger than has been reported in previous work and that the DESW adopts standardised practices and data collection methods, and has the ability to link to other EHR data via the SAIL Databank, which also covers all of Wales.

\section{Acknowledgements}

AA acknowledges financial support from Health Data Research UK (NIWA1), which is funded by the UK

Medical Research Council, Engineering and Physical Sciences Research Council, Economic and Social Research Council, National Institute for Health Research (England), Chief Scientist Office of the Scottish Wellcome. records research infrastructure for Wales. We would like to acknowledge all the data providers who make anonymised data available for research.

\section{What was known?}

- Longitudinal studies have investigated risk factors for diabetic retinopathy in various populations.

- Screening services have improved outcomes and reduced incidence of blindness in people with diabetes. 
- People with type 1 diabetes tend to experience poorer outcomes than those with type 2 diabetes because they often have more difficulty with glycaemic management.

- In our cohort of people with type 1 diabetes $37.4 \%$ had diabetic retinopathy and $10.7 \%$ had referable diabetic retinopathy at first screening.

\section{Bibliography}

1. Hovind P, Tarnow L, Rossing K, Rossing P, Eising S, Larsen N, et al. Decreasing incidence of severe diabetic microangiopathy in type 1 diabetes. Diabetes care. 2003;26(4):1258-64.

2. Klein R, Lee KE, Knudtson MD, Gangnon RE, Klein BE. Changes in visual impairment prevalence by period of diagnosis of diabetes: the Wisconsin Epidemiologic Study of Diabetic Retinopathy. Ophthalmology. 2009;116(10):1937-42.

3. Wong TY, Mwamburi M, Klein R, Larsen M, Flynn H, Hernandez-Medina M, et al. Rates of progression in diabetic retinopathy during different time periods: a systematic review and meta-analysis. Diabetes care. 2009;32(12):2307-13.

M, et al. Changes in the diabetic retinopathy epidemiology after 14 years in a population of Type 1 and 2 diabetic 
patients after the new diabetes mellitus diagnosis criteria and a more strict control of the patients. Journal of diabetes and its complications. 2009;23(4):229-38.

5. Ng SM, Ayoola OO, McGuigan M, Chandrasekaran S. A multicentre study evaluating the risk and prevalence of diabetic retinopathy in children and young people with type 1 diabetes mellitus. Diabetes \& Metabolic Syndrome: Clinical Research \& Reviews. 2019;13(1):744-6.

6. Klein BE. Reduction in risk of progression of diabetic retinopathy. N Engl J Med. 2010;363(3):287-8.

7. Sabanayagam C, Banu R, Chee ML, Lee R, Wang YX, Tan G, et al. Incidence and progression of diabetic retinopathy: a systematic review. Lancet Diabetes Endocrinol. 2019;7(2):140-9.

8. Liew G, Michaelides M, Bunce C. A comparison of the causes of blindness certifications in England and Wales in working age adults (16-64 years), 1999-2000 with 2009-2010. BMJ open. 2014;4(2):e004015.

9. Thomas RL, Luzio SD, North RV, Banerjee S, Zekite A, Bunce C, et al. Retrospective analysis of newly recorded certifications of visual impairment due to diabetic retinopathy in Wales during 2007-2015. BMJ Open. 2017;7(7):e015024.

10. Diabetes Control and Complications Trial Research Group. The effect of intensive treatment of diabetes on the development and progression of long-term complications in insulin-dependent diabetes mellitus. New England journal of medicine. 1993;329(14):977-86.

11. Downie E, Craig ME, Hing S, Cusumano J, Chan AK, Donaghue KC. Continued reduction in the prevalence of retinopathy in adolescents with type 1 diabetes: role of insulin therapy and glycemic control. Diabetes care. 2011;34(11):2368-73.

12. Cleary PA, Dahms W, Goldstein D, Malone J, Tamborlane WV. Beneficial effects of intensive therapy of diabetes during adolescence: outcomes after the conclusion of the Diabetes Control and Complications Trial (DCCT). J Pediatr. 2001;139:804-12.

13. Cho WB, Oh SB, Moon JW, Kim HC. Panretinal photocoagulation combined with intravitreal bevacizumab in high-risk proliferative diabetic retinopathy. Retina. 2009;29(4):516-22.

14. Javitt JC, Aiello LP. Cost-effectiveness of detecting and treating diabetic retinopathy. Annals of internal medicine. 1996;125(11):939-.

15. Holman N, Young B, Gadsby R. Current prevalence of Type 1 and Type 2 diabetes in adults and children in the UK. Diabetic Medicine. 2015;32(9):1119-20.

16. National Paediatric Diabetes Audit Report 2017-18. 2018.

17. Kernell A, Dedorsson I, Johansson B, Wickström C, Ludvigsson J, Tuvemo T, et al. Prevalence of diabetic retinopathy in children and adolescents with IDDM A population-based multicentre study. Diabetologia. 1997;40(3):307-10. 
18. Klein R, Klein BE, Moss SE, Davis MD, DeMets DL. Retinopathy in young-onset diabetic patients. Diabetes care. $1985 ; 8(4): 311-5$.

19. Kubin M, Tossavainen P, Hannula V, Lahti S, Hautala N, Falck A. Prevalence of retinopathy in Finnish children and adolescents with type 1 diabetes: a cross-sectional population-based retrospective study. Archives of disease in childhood. 2011;96(10):963-8.

20. Kullberg C, Abrahamsson M, Arnqvist H, Finnström K, Ludvigsson J. Prevalence of retinopathy differs with age at onset of diabetes in a population of patients with Type 1 diabetes. Diabetic medicine. 2002;19(11):924-31.

21. Maguire A, Chan A, Cusumano J, Hing S, Craig M, Silink M, et al. The Case for Biennial Retinopathy Screening in Children and Adolescents. Journal of American Association for Pediatric Ophthalmology and Strabismus \{JAAPOS $\} .2006 ; 10(2): 189$.

22. LeCaire T, Palta M, Zhang H, Allen C, Klein R, D'Alessio D. Lower-than-expected prevalence and severity of retinopathy in an incident cohort followed during the first 4-14 years of type 1 diabetes: the Wisconsin Diabetes Registry Study. American journal of epidemiology. 2006;164(2):143-50.

23. Falck A, Käär ML, Laatikainen L. A prospective, longitudinal study examining the development of retinopathy in children with diabetes. Acta paediatrica. 1996;85(3):313-9.

24. Geloneck MM, Forbes BJ, Shaffer J, Ying G-s, Binenbaum G. Ocular complications in children with diabetes mellitus. Ophthalmology. 2015;122(12):2457-64.

25. Cahill M, Wallace D, Travers S, Lipinski H, Aldington S, Costigan C, et al. Detection and prevalence of early diabetic retinopathy in juvenile diabetics with diabetes for 10 years or more. Eye. 2000;14(6):847-50.

26. Demirel F, Tepe D, Kara Ö, Esen İ. Microvascular complications in adolescents with type 1 diabetes mellitus. Journal of clinical research in pediatric endocrinology. 2013;5(3):145.

27. Dujić MP, Ignjatović Z. Juvenile diabetes eye complications and treatment. Vojnosanitetski pregled. 2009;66(9):729-32.

28. Florkowski CM, Scott RS, Coope PA, Graham PJ, Moir CL. Age at diagnosis, glycaemic control and the development of retinopathy in a population-based cohort of Type 1 diabetic subjects in Canterbury, New Zealand. Diabetes research and clinical practice. 2001;52(2):125-31.

29. Holl R, Lang GE, Grabert M, Heinze E, Lang G, Debatin K-M. Diabetic retinopathy in pediatric patients with type-1 diabetes: effect of diabetes duration, prepubertal and pubertal onset of diabetes, and metabolic control. The Journal of pediatrics. 1998;132(5):790-4.

30. Olsen BS, Sjølie AK, Hougaard P, Johannesen J, Marinelli K, Jacobsen BB, et al. The significance of the prepubertal diabetes duration for the development of retinopathy and nephropathy in patients with type 1 diabetes. Journal of diabetes and its complications. 2004;18(3):160-4. 
31. Klein R, Klein BE, Moss SE, Davis MD, DeMets DL. The Wisconsin Epidemiologic Study of Diabetic Retinopathy: II. Prevalence and risk of diabetic retinopathy when age at diagnosis is less than 30 years. Archives of ophthalmology. 1984;102(4):520-6.

32. Ghanchi F. The Royal College of Ophthalmologists' clinical guidelines for diabetic retinopathy: a summary. Eye. $2013 ; 27(2): 285-7$.

33. Donaghue K, Wadwa R, Dimeglio L, Wong T, Chiarelli F, Marcovecchio M, et al. Microvascular and macrovascular complications in children and adolescents: Microvascular and macrovascular complications. Pediatric Diabetes. 2014;15:257-69.

34. Grading diabetic retinopathy from stereoscopic color fundus photographs--an extension of the modified Airlie House classification. ETDRS report number 10. Early Treatment Diabetic Retinopathy Study Research Group. Ophthalmology. 1991;98(5 Suppl):786-806.

35. Diabetic retinopathy study. Report Number 6. Design, methods, and baseline results. Report Number 7. A modification of the Airlie House classification of diabetic retinopathy. Prepared by the Diabetic Retinopathy. Invest Ophthalmol Vis Sci. 1981;21(1 Pt 2):1-226.

36. Harding S, Greenwood R, Aldington S, Gibson J, Owens D, Taylor R, et al. Grading and disease management in national screening for diabetic retinopathy in England and Wales. Diabet Med. 2003;20(12):965-71.

37. Thomas RL, Dunstan FD, Luzio SD, Chowdhury SR, North RV, Hale SL, et al. Prevalence of diabetic retinopathy within a national diabetic retinopathy screening service. British Journal of Ophthalmology. 2015;99(1):648.

38. Ford DV, Jones KH, Verplancke J-P, Lyons RA, John G, Brown G, et al. The SAIL Databank: building a national architecture for e-health research and evaluation. BMC health services research. 2009;9(1):157.

39. Lyons RA, Jones KH, John G, Brooks CJ, Verplancke J-P, Ford DV, et al. The SAIL databank: linking multiple health and social care datasets. BMC medical informatics and decision making. 2009;9(1):3.

40. Sayers A, Thayer D, Harvey JN, Luzio S, Atkinson MD, French R, et al. Evidence for a persistent, major excess in all cause admissions to hospital in children with type-1 diabetes: results from a large Welsh national matched community cohort study. BMJ open. 2015;5(4):e005644.

41. Thayer D, Rees A, Kennedy J, Collins H, Harris D, Halcox J, et al. Measuring follow-up time in routinelycollected health datasets: Challenges and solutions. PLoS One. 2020;15(2):e0228545.

42. Klein R, Klein BE, Moss SE, Davis MD, DeMets DL. The Wisconsin Epidemiologic Study of Diabetic Retinopathy: X. Four-year incidence and progression of diabetic retinopathy when age at diagnosis is 30 years or more. Archives of ophthalmology. 1989;107(2):244-9. 
43. Dwyer MS, Melton LJ, Ballard DJ, Palumbo PJ, Trautmann JC, Chu C-P. Incidence of diabetic retinopathy and blindness: a population-based study in Rochester, Minnesota. Diabetes Care. 1985;8(4):316-22.

44. Burger W, Hovener G, Dusterhus R, Hartmann R, Weber B. Prevalence and development of retinopathy in children and adolescents with type 1 (insulin-dependent) diabetes mellitus. A longitudinal study. Diabetologia. $1986 ; 29(1): 17-22$.

45. Malone JI, Morrison AD, Pavan PR, Cuthbertson DD. Prevalence and significance of retinopathy in subjects with type 1 diabetes of less than 5 years' duration screened for the diabetes control and complications trial. Diabetes care. $2001 ; 24(3): 522-6$.

46. Dhillon N, Karthikeyan A, Castle A, Dodson P, Högler W, Kirk J, et al. Natural history of retinopathy in children and young people with type 1 diabetes. Eye. 2016;30(7):987-91.

47. Jansson RW, Hufthammer KO, Krohn J. Diabetic retinopathy in type 1 diabetes patients in Western Norway. Acta ophthalmologica. 2018;96(5):465-74.

48. Hainsworth DP, Bebu I, Aiello LP, Sivitz W, Gubitosi-Klug R, Malone J, et al. Risk factors for retinopathy in type 1 diabetes: the DCCT/EDIC Study. Diabetes care. 2019;42(5):875-82.

49. Sterky G, Wall S. Determinants of Microangiopathy in Growth-onset Diabetes: With Special Reference to Retinupathy and Glycaemic Control. Acta Pædiatrica. 1986;75:1-45.

50. Klein BE, Moss SE, Klein R. Is menarche associated with diabetic retinopathy? Diabetes care. 1990;13(10):1034-8.

51. Kokkonen J, Laatikainen L, Dickhoff K, Miettinen R, Tuominen M, Lautala P, et al. Ocular complications in young adults with insulin-dependent diabetes mellitus since childhood. Acta Paediatrica. 1994;83(3):273-8.

52. Schreur V, van Asten F, Ng H, Weeda J, Groenewoud JM, Tack CJ, et al. Risk factors for development and progression of diabetic retinopathy in Dutch patients with type 1 diabetes mellitus. Acta ophthalmologica. 2018;96(5):459-64.

53. Klein R, Lee KE, Gangnon RE, Klein BE. The 25-year incidence of visual impairment in type 1 diabetes mellitus the wisconsin epidemiologic study of diabetic retinopathy. Ophthalmology. 2010;117(1):63-70.

Figure 1: Proportion of the population with no DR (62.6\%), BDR (26.7\%) or RDR (10.7\%) at first screening and the proportion of people that have PPDR (2.9\%), PDR (2.9\%), maculopathy (2.1\%), PPDR with maculopathy (1.6\%) and PDR with maculopathy (1.2\%) at first screening.

Figure 2: Fraction of persons diagnosed with BDR or RDR at first screening as a function of (a) diabetes duration, (b) age at screening and the fraction of people diagnosed aged less than 12 and aged 12 or older with any DR as a function of diabetes duration (c). 
Table 1: Demographic and laboratory test information on the cohort of people with T1DM at the time of first DR screening event.

395

Table 2: Results from the (a) multivariate binomial logistic regression model (b) multivariate 


\begin{tabular}{|c|c|c|c|c|c|c|c|c|}
\hline Age range & $0-6$ & & $6-12$ & & $12-18$ & & Whole cohort & \\
\hline Description & Count & Median (LQ, UQ) & Count & Median (LQ, UQ) & Count & Median (LQ, UQ) & Count & Median (LQ, UQ) \\
\hline Total n & $851(100 \%)$ & & 1747 (100\%) & & $1592(100 \%)$ & & 4190 (100\%) & \\
\hline Female gender & $425(50 \%)$ & & $914(52 \%)$ & & $631(40 \%)$ & & $1971(47.0 \%)$ & \\
\hline Age at diagnosis (years) & $851(100 \%)$ & $3.47(2.2,4.8)$ & 1747 (100\%) & $9.5(8.0,10.8)$ & $1592(100 \%)$ & $14.2(13.0,15.9)$ & $4190(100 \%)$ & $10.6(7.0,13.4)$ \\
\hline Age at screening (years) & $851(100 \%)$ & $14.2(12.3,21.4)$ & 1747 (100\%) & $14.1(12.4,20.6)$ & 1592 (100\%) & $17.9(15.2,24.0)$ & 4190 (100\%) & $16.3(13.0,22.3)$ \\
\hline Diabetes duration (years) & $851(100 \%)$ & $11.3(8.9,17.9)$ & $1747(100 \%)$ & $5.6(3.1,11.4)$ & $1586(100 \%)$ & $2.7(0.8,9.8)$ & 4186 (99.9\%) & $6.6(2.3,12.3)$ \\
\hline $\mathrm{HbA1c}(\mathrm{mmol} / \mathrm{mol})$ & $390(46 \%)$ & $74.0(65.0,86.8)$ & $822(47 \%)$ & $73.7(63.9,87.7)$ & $743(47 \%)$ & $70.4(56.2,84.6)$ & $1957(46.7 \%)$ & $72.6(61.7,86.0)$ \\
\hline HbA1c (\%) & 390 (46\%) & $8.9(8.1,10.1)$ & $822(47 \%)$ & $8.9(8.0,10.2)$ & 743 (47\%) & $8.6(7.3,9.9)$ & $1957(46.7 \%)$ & $8.8(7.8,10.0)$ \\
\hline Systolic pressure (mmHg) & $383(45 \%)$ & $120.0(110.0,130.0)$ & $814(47 \%)$ & $119.0(110.0,128.0)$ & 931 (59\%) & $120.0(110.0,130.0)$ & $2129(50.8 \%)$ & $120.0(110.0,130.0)$ \\
\hline Diastolic pressure (mmHg) & $383(45 \%)$ & $70.0(62.0,78.0)$ & $814(47 \%)$ & $70.0(63.0,78.0)$ & 931 (59\%) & $70.0(65.0,80.0)$ & $2129(50.8 \%)$ & $70.0(61.0,79.0)$ \\
\hline Cholesterol (mmol/l) & 245 (29\%) & $4.5(3.9,5.1)$ & 507 (29\%) & $4.4(3.8,5.1)$ & $639(40 \%)$ & $4.3(3.7,5.0)$ & $1392(33.2 \%)$ & $4.4(3.8,5.1)$ \\
\hline LDL (mmol/l) & 144 (17\%) & $2.5(2.0,3.0)$ & 302 (17\%) & $2.3(1.8,2.9)$ & 406 (26\%) & $2.3(1.8,2.9)$ & $853(20.4 \%)$ & $2.3(1.8,2.9)$ \\
\hline $\mathrm{HDL}(\mathrm{mmol} / \mathrm{l})$ & 162 (19\%) & $1.5(1.3,1.7)$ & 334 (19\%) & $1.4(1.2,1.7)$ & $438(28 \%)$ & $1.3(1.1,1.6)$ & 935 (22.3\%) & $1.4(1.2,1.7)$ \\
\hline Creatinine $(\mu \mathrm{mol} / \mathrm{l})$ & 203 (24\%) & $76.0(64.5,89.0)$ & 469 (27\%) & $73.0(63.0,85.0)$ & $656(41 \%)$ & $74.0(63.0,86.0)$ & 1330 (31.7\%) & $74(63,86)$ \\
\hline BMI (kg/m2) & $294(35 \%)$ & $23.8(21.12,27.2)$ & $611(35 \%)$ & $23.4(21.1,26.7)$ & 784 (49\%) & $24.0(21.3,27.0)$ & 1691 (40.4\%) & $23.8(21.1,26.9)$ \\
\hline
\end{tabular}

$\mathrm{BMI}(\mathrm{kg} / \mathrm{m} 2)$

\begin{tabular}{l|l}
$294(35 \%)$ & $23.8(21.12,27.2$ \\
\hline
\end{tabular} 
(a)

\begin{tabular}{c|c}
\hline Variable & OR (95\% CI), No \\
DR vs. Any DR \\
\hline Diabetes duration (diagnosed $<12)$ & $1.23(1.20,1.26)$ \\
Diabetes duration (diagnosed $>=12)$ & $1.34(1.30,1.37)$ \\
$\mathrm{HbA}_{1 \mathrm{c}}($ per $10 \mathrm{mmol} / \mathrm{mol})$ & $1.09(1.04,1.15)$ \\
\hline
\end{tabular}

401

$R_{N}{ }^{2}=0.7 \overline{64}$

402

$A=0.827$

403

(b)

\begin{tabular}{c|c|c}
\hline Variable & $\begin{array}{c}\text { OR (95\% CI), No } \\
\text { DR vs. BDR }\end{array}$ & $\begin{array}{c}\text { OR (95\% CI), } \\
\text { No DR vs. RDR }\end{array}$ \\
\hline Diabetes duration (diagnosed < 12) & $1.22(1.19,1.24)$ & $1.29(1.26,1.33)$ \\
Diabetes duration (diagnosed > 12$)$ & $1.32(1.29,1.36)$ & $1.40(1.36,1.44)$ \\
$\mathrm{HbA}_{1 \mathrm{c}}($ per 10mmol/mol) & $1.07(1.02,1.14)$ & $1.19(1.10,1.29)$ \\
Diastolic pressure & $1.02(1.01,1.04)$ & $1.04(1.02,1.06)$ \\
\hline
\end{tabular}

404

$R_{N}^{2}=0.782$

405

$A=0.721$

406

407 


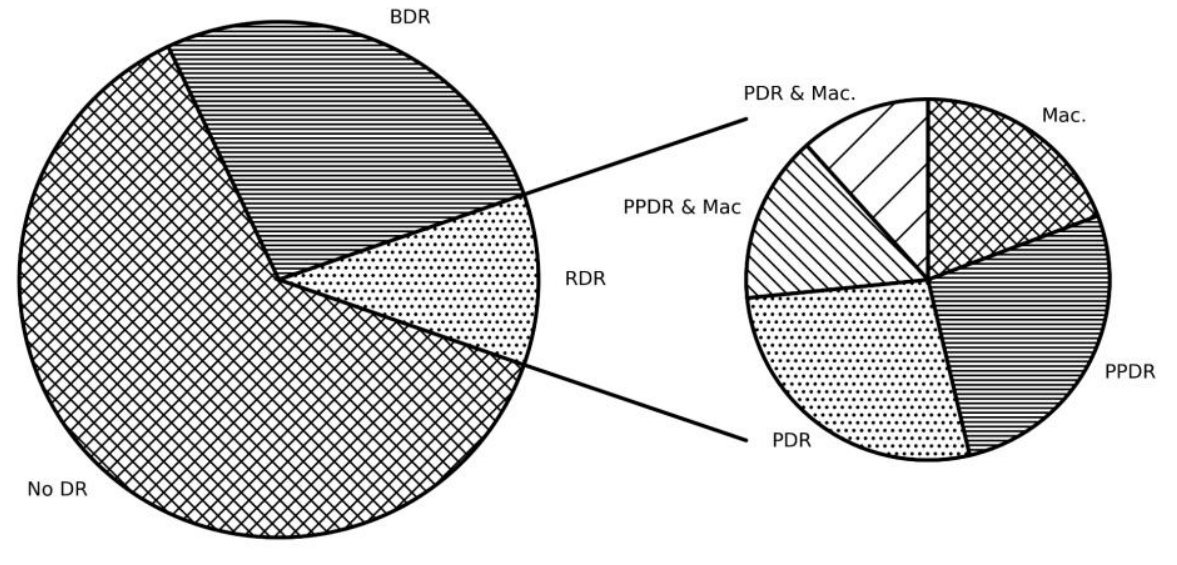

408

409

410 

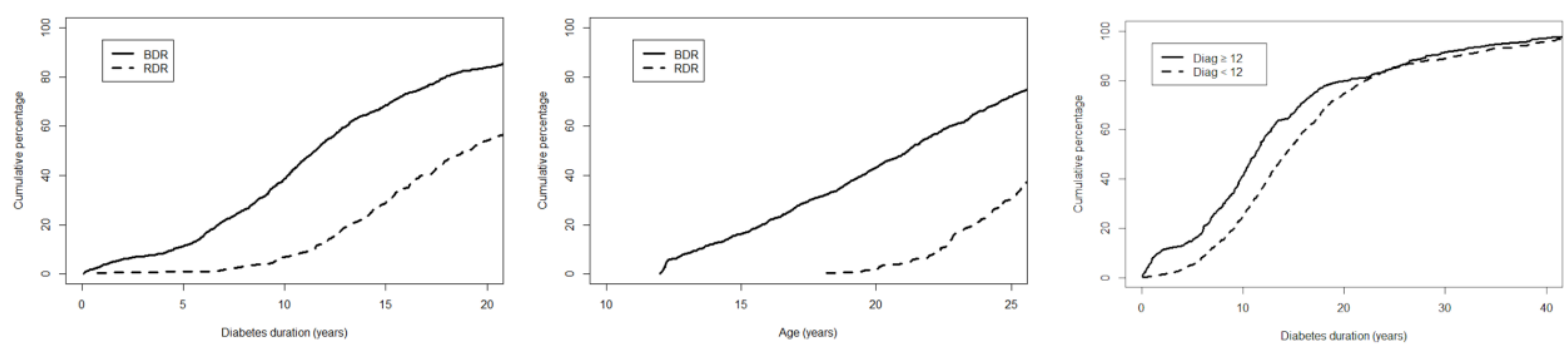